\title{
Process and Outcome
}

\section{Obstetric audit in general practice}

\author{
G N MARSH
}

British Medical fournal, 1977, 2, 1004-1006

\begin{abstract}
Many recent papers have tried to show how inadvisable it is for general practitioners to undertake obstetric care and more especially obstetric deliveries. ${ }^{1-3}$ The high proportion of artificially induced labours, the enthusiasm for the increasing "mechanisation" of labour, descriptions of unexpected and sinister disease that the inexperienced obstetrician would not detect have all made general practitioners less confident in obstetrics. By virtue of the very breadth of their specialty GPs find it difficult to aggregate sufficient numbers of cases to refute the allegations of mediocrity made about their obstetric care and the possibly poor obstetric outcome achieved by them.

I will describe the results of the obstetric care in a practice that works closely with a specialist unit, and they are far superior to national averages. With the development of effectively functioning primary health care teams, increasingly containing vocationally trained general practitioner obstetricians, ${ }^{4}$ encouragement of this style of obstetric care could improve the overall national statistics.

We believe that modern obstetrics should aim at normal pregnancy, labour, delivery, puerperium, and a healthy mother and breast-fed baby. Care should take place in a setting that the mother, after consulting her obstetrician, be he general practitioner or specialist, believes to be in the best interests of herself and her baby, not only physically but also socially and psychologically. When patient participation is becoming increasingly encouraged obstetrics above all specialties should be the one in which the mother's wishes and desires are met, as well as the rather narrower clinical dictums of the obstetrician himself." Future perinatal, neonatal, and maternal mortality and morbidity statistics will increasingly be viewed not in absolute terms but will be set against the amount of deviation from the normal process described above. Anderson, Turnbull, and Baird ${ }^{6}$ suggested that since the health of pregnant women was improving and the maternal age at first birth was falling, the need for obstetric interference should actually be getting less. We have attempted to implement that suggestion.
\end{abstract}

\section{Method}

The practice is situated in urban north-east England, and most of the patients are from social classes III and IV, living in local authorityowned houses. A considerable number of patients live in squalid social circumstances, and there are some single-parent families. Conversely, there are one or two estates of mostly social classes I and II patients. Altogether, there is insufficient variation from national

Stockton on Tees, Cleveland

G N MARSH, MD, DOBSTRCOG, general practitioner social class figures to cause any significant change in the perinatal mortality rate.

The audit covers a 15-year period from 1962 to 1976, when 701 consecutive pregnancies on one doctor's list were looked after to beyond the 28 th week of gestation.

During those years the practice developed from a fairly simple doctor, nurse, receptionist triad into a comprehensive primary health care team working in conveniently placed premises at the centre of the practice area. ${ }^{i}$ The obstetric segment within the team comprises filing clerks to ensure immediate availability of comprehensive records; receptionists and nurses to run antenatal clinics; midwives to carry out the obstetric routines and protocols; health visitors to supervise the overall health care of the pregnant women and to run relaxation and motherhood classes; a family planning nurse to interview all patients during the antenatal period and again at the postnatal examination; and social workers and marriage counsellors to deal with various non-obstetric psychological and social problems that arise during pregnancy and puerperium. It is a community-orientated, multidisciplinary team of professionals, each with a high regard for the expertise of the other. It is a democratic team, not a hierarchical one, and the general practitioner is the co-ordinator. The team members meet each morning as part of the comprehensive primary health care team meeting when problems can be discussed and patient management shared and planned.

The team carried out the antenatal care and postnatal examination of all mothers regardless of their delivery arrangements, although those booked for specialist delivery attended specialist clinics at the hospital at the discretion of the specialist. Such patients normally attended only two or three times. From 1962 to 1968 the general practitioner-booked cases were delivered in an isolated general practitioner maternity home about seven minutes' distance from the practice medical centre. Bookings for this unit were left to the general practitioner's discretion, and a specialist made himself available once a week at the unit to see any problem patients that either the general practitioner or the nursing staff at the maternity unit identified in the antenatal period. If any difficult problems arose in labour patients had to be transferred by ambulance to a specialist unit seven miles away. At that time domiciliary obstetrics were fairly widely practised.

In 1968 the general practitioner maternity home closed and was rehoused on the first floor of a new district maternity hospital only five minutes away from the practice centre. The three floors above were used by the specialist obstetricians for abnormal cases. In common with all the other general practitioners in the area, the practice booked cases for the general practitioner unit, and all such cases were assessed by a senior hospital midwife. If the risk categories of a patient appeared to make booking into the specialist unit more advisable then the notes were brought to a monthly booking committee consisting of general practitioners, specialists, and senior midwifery staff. Their consensus view decided whether the case was left for the general practitioner unit or passed to specialist care delivery.

The doctors in the practice provided 24-hour availability, not only of themselves but also of an equally qualified deputy (their partner). Practice policy has always been that regardless of off-duty hours and weekends, it is the partner who has given the antenatal care who will carry out care in labour. Hence the normal off-duty rota excludes obstetrics and operates only when the doctor concerned is actually away. All the partners believed that they should visit during the first stage of labour and be present at delivery because of the problems of the unexpectedly distressed baby or haemorrhaging mother. More commonly, however, mothers preferred to be encouraged by the 
obstetrician who had supported her psychologically as well as physically during the antenatal period. It is also becoming increasingly important to assess the maternal response to the baby to try to identify any future nurturing problems.

\section{Results}

Of 701 consecutive pregnancies proceeding beyond 28 weeks' gestation, $269(38.4 \%)$ were primigravidae and $432(61.6 \%)$ multigravidae. We booked $138(19.7 \%$ ) patients for home delivery and 453 $(64.6 \%)$ for general practitioner unit delivery-that is, $591(84.3 \%)$ and $110(15.7 \%$ ) for specialist booking. By the time delivery had taken place $497(70.9 \%)$ were delivered by the general practitioner and 204 $(29.1 \%)$ by the specialist obstetric unit because abnormalities had developed.

There were four stillbirths and two neonatal deaths scattered fairly evenly throughout the period, giving an overall average perinatal mortality rate of 8.5 deaths per 1000 births-less than half the national and area averages (see figure).

The delivery method in the practice series is compared with the 1970 British Births Survey, ${ }^{8}$ and some provisional figures from Newcastle upon Tyne (table I). Accepting the different timing of the three series, the practice shows a significantly higher percentage of

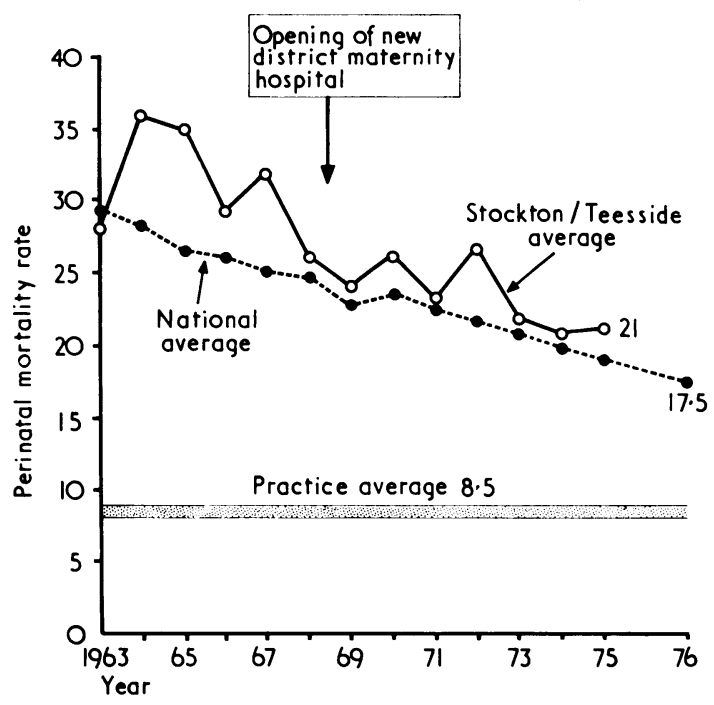

Perinatal mortality rates compared with national and area averages.

TABLE I-Comparison of delivery methods

\begin{tabular}{|c|c|c|c|c|c|c|}
\hline & & & $\begin{array}{c}1958 \\
\text { Perinatal } \\
\text { Problems } \\
\text { per cent }\end{array}$ & $\begin{array}{c}1970 \\
\text { British } \\
\text { Births } \\
\text { per cent }\end{array}$ & $\begin{array}{c}1975 \\
\text { Provisional } \\
\text { Newcastle } \\
\text { upon Tyne } \\
\text { per cent }\end{array}$ & $\begin{array}{l}\text { Practice } \\
1962-76 \\
\text { per cent }\end{array}$ \\
\hline $\begin{array}{l}\text { Spontaneous vertex } \\
\text { Forceps to vertex } \\
\text { Breech . . } \\
\text { Caesarean section } \\
\text { Other .. . .. }\end{array}$ & $\begin{array}{l}\ldots \\
\ldots \\
\cdots \\
\cdots\end{array}$ & $\begin{array}{l}\ldots \\
\cdots \\
\cdots \\
\cdots\end{array}$ & $\begin{array}{r}88 \cdot 2 \\
4 \cdot 7 \\
2 \cdot 3 \\
2 \cdot 7 \\
2 \cdot 2\end{array}$ & $\begin{array}{c}83 \cdot 7^{*} \\
7 \cdot 9 \\
2 \cdot 5 \\
4 \cdot 5 \\
1 \cdot 4\end{array}$ & $\begin{array}{l}73 \cdot 5^{*} \\
15 \cdot 7^{*} \\
2 \cdot 4 \\
8 \cdot 0^{*} \\
0 \cdot 4\end{array}$ & $\begin{array}{c}88 \cdot 4+ \\
6 \cdot 5+ \\
1 \cdot 7 \\
3 \cdot 4+\end{array}$ \\
\hline
\end{tabular}

${ }^{*}+=$ highly significant difference $(P<0.01)$.

TABLE II-Changes in obstetric practice: 1962-8 and 1968-76

\begin{tabular}{|c|c|c|c|}
\hline & & $\begin{array}{c}1962-8 \text { (354 deliveries) } \\
\text { per cent }\end{array}$ & $\begin{array}{c}1968-76 \text { ( } 351 \text { deliveries) } \\
\text { per cent }\end{array}$ \\
\hline $\begin{array}{l}\text { Booked GP } \\
\text { Booked consultant } \\
\text { Delivered GP } \\
\text { Delivered consultant } \\
\text { Spontaneous vertex } \\
\text { Forceps to vertex } \\
\text { Brech delivery } \\
\text { Caesarean section }\end{array}$ & $\begin{array}{l}\ldots \\
\cdots \\
\cdots \\
\cdots \\
\cdots \\
\cdots\end{array}$ & $\begin{array}{l}89 \cdot 4^{*} \\
10 \cdot 6^{*} \\
80 \cdot 0^{*} \\
20 \cdot 0^{*} \\
91 \cdot 8^{*} \\
4 \cdot 0^{*} \\
1 \cdot 7 \\
2 \cdot 5\end{array}$ & $\begin{array}{l}79 \cdot 2+ \\
20 \cdot 8+ \\
61 \cdot 8+ \\
38 \cdot 2+ \\
84 \cdot 9+ \\
9 \cdot 1+ \\
1 \cdot 7 \\
4 \cdot 3\end{array}$ \\
\hline
\end{tabular}

$*_{+}^{+}=$highly significant difference $(P<0.01)$. Total of 705 births includes four sets of twins. spontaneous vertex deliveries than both the other series and a significantly lower percentage of forceps deliveries and caesarean sections compared with the area figures from Newcastle.

After the opening of the general practitioner unit in the district maternity hospital and the operation of the formal booking committee the number of patients booked for specialist care has risen significantly as have the numbers delivered in the specialist unit (table II). The number of spontaneous vertex deliveries has fallen significantly and the number of forceps deliveries has also risen significantly.

\section{Discussion}

There are probably several reasons why the results from this audit should be so much better, yet obstetrically more "normal" than national and local averages. Major credit must go to the whole primary health care obstetric team and especially to its co-ordinated and comprehensive system of antenatal care.

Increasingly, the team has orientated more on the socially deprived and "non-attending" members of the pregnant community and to some extent has withdrawn some of the ritualised antenatal care of the very low risk cases. Accordingly, the practice now operates different protocols of care for different types of patient. The unmarried and social classes IV and V patients having their first baby, teenagers, primiparae with a history of previous miscarriage, and grand multiparae are seen more often by midwife, doctor, and health visitor and haemoglobin checks are carried out more often. Midwife home visits after non-attendance for antenatal appointments are routine in this group. Conversely, patients assessed by the doctor as low risk are passed to midwife care up to the 32nd week and the midwife thus enjoys and fulfils a personal responsibility for detecting occasional abnomality in this group. After 32 weeks doctor and midwife carry out dual care of all patients.

Credit accrues to the hospital specialists, who have obviously managed extremely well the more difficult problems that the team identified, assessed, and referred to them. With a GP: specialist ratio of deliveries of $71: 29$ the perinatal mortality rate averaged $8 \cdot 5$, whereas parallel statistics from the British Births Survey ${ }^{8}$ showed that with a 1:2 GP:specialist ratio the perinatal mortality rate was $23 \cdot 5$. Hospital specialists have been criticised repeatedly for delegating severely ill and problem patients to inadequately experienced junior staff, ${ }^{8}{ }^{9}$ and possibly one reason for our better figures is that specialist colleagues have been "protected" from many normal or near normal cases by enthusiastic general practitioner obstetricians and could therefore undertake a greater degree of personal high quality, high level supervision of the fewer patients passed to them.

The reason for the higher proportion of normal deliveries is probably twofold. Firstly, the continuing and personal care and encouragement of the long-known patient by the long-known doctor during labour is at the same time of immeasurable and yet probably of inestimable value. Secondly, the general practitioner working in a normal unit cannot and does not overreact with drips, machines, and other interventions to minor abnormalities or minor delays in potentially normal cases; he merely observes more acutely whether the natural process will see the patient through. Thus he avoids exposing large numbers of normal mothers and children to the risks of unnecessary medical interference on a routine basis. ${ }^{1011}$

The general practitioner unit is used actively by almost every practice in the town. It encouraged the introduction of the father into the delivery room and now has some fathers present for forceps deliveries and perineal repairs. In the setting of a normal unit it has been possible to encompass some of the principles of the Leboyer technique for gentle delivery of the fetus. ${ }^{12}$ Preparation for breast-feeding begins in early pregnancy and is carried right through to beyond time of discharge.

The general practitioner unit houses a small early-discharge unit, where patients are delivered by the district midwife and return home after a few hours. Increasingly the practice is encouraging earlier discharge of all mothers, including primigravidae, and with a co-ordinated community team available 
there is no doubt that obstetric beds could be reduced and hospital care rendered less expensive by earlier and earlier discharge. ${ }^{13}$ Because of his personal knowledge of the patient and the availability of a community team to him, the general practitioner can obviously be expert in timing the return home of mothers and babies from hospital; increasingly the specialists are acquiescing in general practitioners carrying out the puerperal care not only of "GP cases" but also higher risk cases delivered in the specialist unit. Indeed, with results as good as have been achieved in this particular audit, and after careful case selection, the time may well have arrived when requests for home delivery of low risk cases could be acceded to. ${ }^{1-16}$

Not all practices will wish to participate nor even be geographically able to undertake this type of obstetric care, but when interest, expertise, enthusiasm, and geography are favourable and coexist our style of care could improve the overall national figures and serve as a standard by which the increasingly fashionable specialist-orientated obstetric care could be measured.

I am extremely grateful for the sustained support of my partners and trainees, the whole primary health care team, the general practitioners obstetric unit staff, and my local specialist obstetric colleagues during this audit. Credit for the results is attributable to all of them.

I am most grateful to $\mathrm{Dr} \mathrm{K}$ W Cross, Department of Social Medicine, University of Birmingham, for analysing the early part of the statistics.

\section{References}

${ }^{1}$ Cox, C A, et al, British Medical fournal, 1976, 1, 84.

2Curzon: P, and Mountrose, U M, British Medical fournal, 1976, 2, 1433.

Chamberlain, G, British Medical fournal, 1977, 1, 168.

4 Joint Working Party of Representatives of the Royal College of Obstetricians and Gynaecologists and the Royal College of General Practitioners, fournal of the Royal College of General Practitioners, 1974, 24, 355.

${ }^{5}$ Kitzinger, S, Some Mothers' Experience of Induced Labour. London, National Childbirth Trust, 1975.

${ }^{6}$ Anderson, A B, Turnbull, A C, and Baird, D, fournal of Obstetrics and Gynaecology of the British Commonwealth, 1968, 75, 271.

${ }^{7}$ Marsh, G N, and Kaim-Caudle, P, Team Care in General Practice. London, Croom Helm, 1976.

${ }^{*}$ Chamberlain, R, et al, British Births, 1970, vol 1. London, Heinemann Medical, 1975.

${ }^{9}$ Department of Health and Social Security, Report on confidential enquiries into Maternal Deaths in England and Wales, 1970-2. London, HMSO, 1975.

10 O'Driscoll, K, Carroll, C J, and Coughlan, M, British Medical fournal, $1975,4,727$.

${ }^{11}$ Meagher, D, and O'Driscoll, K, British Medical fournal, 1977, 1, 708.

12 Leboyer, F, Birth Without Violence. London, Wildwood House, 1975.

${ }^{13}$ Department of Health and Social Security, Priorities for Health and Personal Social Services in England. London, HMSO, 1976.

${ }^{14}$ Hudson, C K, Practitioner, 1968, 201, 816.

${ }^{15}$ Zander, L, Fournal of Maternal and Child Health, 1976, 14, November.

16 Goldthorpe, W O, and Rishman, J, Practitioner, 1974, 212, 845.

17 Butler, N R, and Bonham, D G, First Report of 1958 British Perinatal Mortality Survey, Perinatal Problems. Edinburgh, Livingstone, 1963.

(Accepted 23 August 1977)

\section{Return to work}

\section{A BREWERTON, P J R NICHOLS}

British Medical fournal, 1977, 2, 1006-1007

We write as individual consultants with responsibilities for the rehabilitation of people with physical disabilities and with a particular interest in the problems of returning the sick, injured, and disabled to work.

Resettlement in work should be a major objective of the National Health Service. It is of great importance to the productivity of the nation, as well as the contentment and self-respect of the individuals concerned. Regrettably, two facts are obvious. There is a deplorable gap between the medical profession and the employment services and, apart from the Mair Report ${ }^{1}$ in Scotland, there has been no adequate review of this important subject for over 20 years. It was not considered by the Tunbridge Committee on rehabilitation."

\section{Services}

At the time of the Tomlinson Report ${ }^{3}$ in 1943 the essential aim

\section{Westminster Hospital, London SW1}

D A BREWERTON, MD, FRCP, consultant in rheumatology and rehabilitation

Mary Marlborough Lodge, Nuffield Orthopaedic Centre, Oxford
OX3 7LD
P J R NICHOLS, DM, FRCP, consultant physician in rehabilitation

was to help injured servicemen returning from the war. Most of them would have permanent, readily defined disabilities. Clearly, it was necessary to establish centres to assess these men and women, and to retrain many of them for new jobs. This was primarily an employment problem. Provided doctors, psychologists, and social workers were available in the centres to advise, it was logical for experts in employment to organise and manage the service, and for the whole to come under the Ministry of Labour. Given an opportunity to start afresh, it is very doubtful whether any committee reviewing the facilities and problems today would make similar proposals. Unfortunately the ideal would require fundamental changes. Nevertheless, it should be emphasised that the existing structure of the employment services was planned before the National Health Service had started. Since the war medical rehabilitation has developed steadily and its facilities are now more evenly spread throughout the country. There have been major changes in the social services and in the provision of education, housing, and other services for the disabled. The remedial therapists have increased in number and adopted new roles. Recently there has been a major increase of services within the community, and more help has been given to general practitioners.

\section{Change in patients}

It is not only the services that have changed, so have the patients. Today, those people who require retraining for an 